\title{
Screening for Potential Plant Growth-Promoting Rhizobacteria (PGPR) Associated with Five Musa spp. Cultivars in SOCCSKSARGEN, Philippines
}

\author{
Giuseppe Haydn Lacorte ${ }^{12}$, Remedios S. Flamiano ${ }^{1}$, Malona V. Alinsug ${ }^{1}$ and \\ Paolo M. Tagaloguin ${ }^{1}$ \\ ${ }^{1}$ Science Department, College of Natural Sciences and Mathematics, Mindanao State University-General \\ Santos City \\ ${ }^{2}$ (Corresponding author: rabbi041396@gmail.com)
}

Received: September 19, 2017; Accepted: March 19, 2018

\begin{abstract}
Rhizospheric bacteria (PGPR) associated with 5 banana cultivars planted in SOCCSKSARGEN were studied. Microbial population in newly established and old plantation was compared. Bacteria were purified and their beneficial characteristics were determined. This study was able to collect one hundred twenty (120) bacterial isolates, 20 (17\%) of which were nitrogen-fixers, nineteen (19/20) were phosphate solubilizers and seventeen (17/20) were IAA producers. From this study, five bacterial isolates coded PE05, RS10, PE11, PE13, and PE18 were found positive for nitrogen fixation, phosphate solubilization and IAA production which may be further evaluated for their potential application in the formulation of biofertilizers for banana cultivation.
\end{abstract}

Keywords: rhizobacteria, biofertilizer, phosphate, nitrogen, indole-3-acetic acid

Banana is one of the most widely grown fruit crops in the Philippines. It is a significant source of revenue for the country, and an important livelihood to about 5000 families. Due to its profitability, banana plantations especially in Mindanao have increased significantly (Department of Agriculture, 2017).

It has been observed that banana cultivation in many parts of this country has become heavily dependent on inorganic chemical inputs which are preferred by many growers because chemical fertilizers are fast acting, and they become readily available to plants for absorption in contrast to organic fertilizers (Mtambanengwe, Kosina, \& Jones, 2007). This heavy dependence on chemical fertilizers by farmers may have adverse impact to environment degradation such as leaching, pollution of water resources, destruction of microorganisms and friendly insects, and crop susceptibility to various diseases. It has been reported that heavy inorganic inputs have been demonstrated to reduce the colonization of plant roots with mycorrhizae and inhibit symbiotic $\mathrm{N}$ fixation by rhizobia due to high $\mathrm{N}$ fer- tilization and enhance the decomposition of soil organic matter, which leads to degradation of the soil structure (Chen, 2004). Hence, in an effort to mitigate environment degradation from heavy chemical fertilization, studies for better alternatives in the cultivation of plantation crops without relying on inorganic fertilizers is important in modern agriculture. One promising alternative to inorganic fertilizers is the identification of live microorganisms such as PGPRs with beneficial properties to promote plant growth and inhibit pathogens.

As defined by Kloepper and Scroth (1978), PGPRs are microorganisms that, after being inoculated on seeds, could successfully colonize plant roots and positively enhance plant growth. They are root-colonizing bacteria that form symbiotic relationships with their plant hosts (Vessy, 2003). These rhizobacteria have the potential to enhance the growth of their plant hosts (in the absence of potentially pathogenic microorganisms) by solubilizing normally poor soluble nutrients in the soil, by lowering the soil $\mathrm{pH}$ by secreting various acidic organic compounds (van Loon, 2007). In addition, 
plant growth promotion can also occur indirectly through the control of certain pathogens (biocontrol) via the synthesis of secondary metabolite-mediated induced systematic resistance (ISR) (van Loon, Bakker, \& Pieterse, 1998). Rhizobacteria are prevalent on or within the roots of plants and along the rhizosphere or the zone between the surface of the root and the soil adjacent to the roots (Nasrin \& Rahman, 2007) which usually contains dense and active microbial populations that are capable of exerting beneficial, neutral and detrimental influences on the plants (Kumar, Kumar, Devi, Patil, Payal, \& Sushila, 2012). This plant-microbe interaction that occurs in the rhizosphere is responsible for the increase in plant health as well as the overall fertility of the soil (Khan, Zaidi, \& Wani, 2006). It is therefore interesting to know what microorganisms are present in the rhizosphere microbiome along with the functions they play on the overall health of the plant to be able to efficiently enhance plant growth and health (Mendes, Garveba, \& Raajimakers, 2013). Agriculturally, these beneficial bacteria can be utilized as inoculants intended for certain crops and plants. Biofertilizers that contain living microorganisms, when applied to the soil, plant surfaces, or seeds can promote growth through increasing the availability or supply of the primary nutrients needed by the host plant.

In this study, rhizospheric bacteria associated with five different banana cultivars were studied; their beneficial characteristics were determined and quantified for possible consideration in the development of inoculum for commercial banana plantation. .

\section{Materials and Methods}

\section{Place of Study}

SOCCSKSARGEN, Philippines is geographically located at Central Mindanao that lies between $06^{\circ} 30^{\prime} \mathrm{N}-124^{\circ} 51^{\prime} \mathrm{E}$. Five newlyestablished (1-6 years) and five old ( $\geq 7$ years) banana plantations in SOCCSKSARGEN cultivating the five major banana cultivars namely: Cardava/ Saba, Lacatan-Lakatan, Latundan-Tundan, Bungulan and Cavendish were selected for the collection of samples to compare the microbial populations along the rhizospheres of each cultivar grown in newly established and old plantations in SOCCSKSARGEN, Philippines. The precise locations of the sites were determined through GPS (Table 1).

\section{Collection of the Soil and the Banana Root Sam- ples}

Soil and root samples were collected from the rhizospheres and roots of different Musa spp. (banana) cultivars growing at various plantations in SOCCSKSARGEN, Philippines. Collection of the rhizospheric soil and banana root samples were based upon the three zones of the rhizosphere defined by Mcnear (2013). These zones include the ectorhizosphere the outermost zone of the rhizosphere which extends from the rhizoplane into the bulk soil, the rhizoplane which is the medial zone directly adjacent to the plant roots that includes the root epidermis and mucilage and the endorhizosphere that includes portions of the cortex and endodermis of the roots. Samples were taken from these zones and were processed separately for the direct microbial count and isolation of potential PGPRs.

The ectorhizosphere samples were taken randomly from the ectorhizospheric zones of different banana plants across the perimeter of the plantations (2-10 ha). Soil samples were acquired by digging at least five inches of soil below the desired banana plant. About a handful of soil samples were taken and were placed carefully within a sealed plastic bag. The soil samples that were acquired from the plantation were combined into one bulk sample. Soil collection was continued until 2 $\mathrm{kg}$ (4.41 lb.) of ectorhizospheric soil samples were obtained from every plantation.

Plantation soil samples were taken randomly along the vicinity of the banana plantations. Soil samples were taken from the soil that was about two meters away from the banana plants. Samples were acquired by digging at least five inches soil below the ground and retrieving at least a handful of soil in that area. This process was continued until most of the area of the plantation was sampled (about 2-7 ha) or until about $2 \mathrm{~kg}(4.41 \mathrm{lb}$.) of soil samples were obtained.

Root samples were taken from healthy banana plants grown within the plantations. These root samples were used for the direct microbial count and isolation of beneficial bacteria from the endorhizosphere and rhizoplane of banana plants. Root samples were obtained by digging out intact banana roots and removing them from the plant by carefully cutting at the crown with a sharp razor blade. Excess soil was removed from the roots by agitating the contents of each bag enough to dislodge the soil particles off the roots. Root samples were taken from different banana plants across the 
JEEAR, Vol. 1, 2018

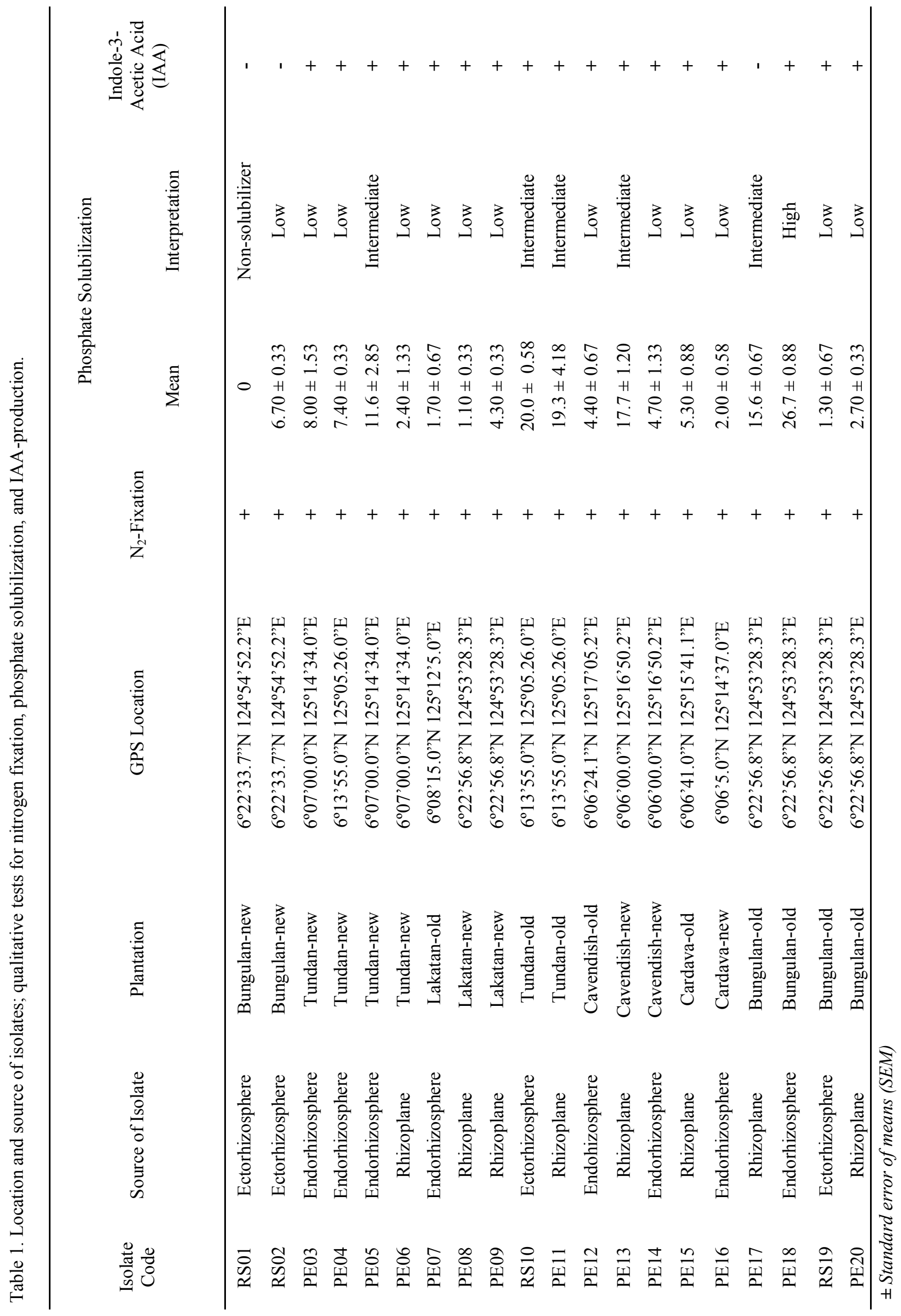


vicinity of the plantations until $1.5 \mathrm{~kg}(3.31 \mathrm{lb}$.) of samples were obtained. One bag of root samples per cultivar from newly-established plantations and one bag of root samples per cultivar from old plantations were collected. A total of ten bags of root samples were acquired from ten sampling sites and were stored away from direct sunlight exposure. A total of ten independent bags of rhizospheric soil, plantation soil and root samples were collected for the direct plate counting and isolation of the bacterial isolates.

\section{Preparations for the Ectorhizosphere and Plan- tation Soil Samples}

The soil samples were sieved to remove debris and large clumps of soil. Ten grams $(10 \mathrm{~g})$ of the sieved soil were subjected to serial dilution. The $10^{-5}$ to $10^{-7}$ dilutions were spread-plated on Nutrient (NA) and the plates were incubated at $30 \pm 0.1^{\circ} \mathrm{C}$ for $24-28$ hours.

\section{Preparations for the Rhizoplane Root Samples}

Roots were agitated to remove loosely adhering soil particles. Large root samples were cut off into manageable pieces ( $\sim 3$ inches) and were weighed on a digital balance to acquire a $10 \mathrm{~g}$ sample. The samples were immediately subjected to a ten-fold serial dilution and spread plated on NA. Plates were incubated at $30 \pm 0.1^{\circ} \mathrm{C}$ for $24-28$ hours. The plated samples would represent the microbial populations of the rhizoplane.

\section{Preparations for the Endorhizosphere Root Samples}

Collected banana root samples were thoroughly rinsed in running tap water to eliminate loosely adhering soil particles on the root surface. Roots were subjected to surface sterilization using $70 \%$ ethanol for $2 \mathrm{~min}$ and immersed in $150 \mathrm{ml}$ of $1.5 \%$ sodium hypochlorite and five drops of Tween 80 for 5 min with gentle stirring. The samples were then rinsed thoroughly in five changes of sterile distilled water and dried in sterile paper towels. The surface sterilized samples were homogenized with a sterile mortar and pestle and then run for serial dilution as prescribed by Johnson and Curl (1972). Dilutions were spread-plated on NA. The plates were incubated at $30 \pm 0.1{ }^{\circ} \mathrm{C}$ for $24-28$ hours. The growth represented the endorhizospheric microbial populations.

\section{Direct Plate Counting}

After the sample preparations, $100 \mu 1$ of the aliquots from the $10^{-5}-10^{-7}$ dilutions from the ectorhizospheric and plantation soil samples and the $10^{-}$ ${ }^{3}-10^{-5}$ dilution factors from the rhizoplane and endorhizospheric root samples were spread plated on prepared Nutrient Agar in triplicates. The plates were incubated for at least 24-48 hours prior to colony counting to ensure that enough colonies will grow on the medium. The number of colonies that appear on each of the plates having 30 and 300 colonies were considered (Tortorra, Funke, and Case, 2010). Mean colony counts were obtained (Table 2 and Table 3). To calculate the estimated number of bacteria on the surface of the medium, the following formula was used (Tortorra, 2010):

$$
B=\frac{N}{d}
$$

where $\mathbf{B}=$ the number of bacteria(CFU/g); $\mathbf{N}=$ the average number of colonies counted on all the plates per dilution; $\mathbf{d}=$ dilution factor; The average for multiple dilutions that fell within the range was reported as the final CFU/g for that sample.

Means were analyzed by $t$ test using PAST Statistical Software v.3.0 (Hammer, Harper and Ryan, 2005).

\section{Isolation of Nitrogen-fixing bacteria}

Individual colonies from the soil, rhizoplane and endorhizosphere root samples were repeatedly streaked on Nutrient Agar until pure colonies were obtained. Each individual isolate were then inoculated on prepared Jensen's medium and were incubated for at least 2 days. Any isolate that grew on the medium was considered $\mathrm{N}_{2}$-fixing (Vincent, 1970). All bacteria positive for $\mathrm{N}_{2-}$ fixation were tested for phosphate solubilization and IAA production. Only isolates positive for $\mathrm{N}_{2-}$ fixation, phosphate solubilization and IAA production were considered the most promising for the development of biofertilizers for banana crops.

\section{Isolation and Qualitative Test for Phosphate Solubilization}

All the $\mathrm{N}_{2}$-fixing isolates were screened for phosphate solubilization on Pikovskaya's Agar. Each isolate was inoculated on prepared Pikovskaya's Agar through spot inoculation technique in triplicates and were incubated at room temperature for four days. Isolates developing clear 
JEEAR, Vol. 1, 2018

Table 2. $\mathrm{T}$ tests for the ectohizosphere and plantation soil samples from newly-established and old banana plantations in SOCCSKSARGEN.

\begin{tabular}{|c|c|c|c|}
\hline \multicolumn{4}{|c|}{$\begin{array}{r}t \text { Test for Ectohizosphere vs. Plantation soil } \\
\text { Mean Microbial counts (in } \log \text { values) }\end{array}$} \\
\hline Cultivar & Ectorhizosphere (cfu/g) & Plantation soil (cfu/g) & $p$ \\
\hline Bungulan New & $8.04 \pm 0.015$ & $7.90 \pm 0.020$ & $0.005185^{*}$ \\
\hline Bungulan Old & $7.86 \pm 0.012$ & $7.68 \pm 0.020$ & $0.004643^{*}$ \\
\hline Cavendish New & $8.25 \pm 0.006$ & $8.15 \pm 0.014$ & $0.009627^{*}$ \\
\hline Cavendish Old & $8.02 \pm 0.019$ & $7.99 \pm 0.020$ & 0.3984740 \\
\hline Cardava New & $8.25 \pm 0.008$ & $8.05 \pm 0.022$ & $0.006466^{*}$ \\
\hline Cardava Old & $8.00 \pm 0.013$ & $7.94 \pm 0.012$ & 0.0175700 \\
\hline Lakatan New & $8.08 \pm 0.027$ & $8.05 \pm 0.047$ & 0.4052140 \\
\hline Lakatan Old & $7.96 \pm 0.027$ & $7.93 \pm 0.011$ & 0.4862890 \\
\hline Tundan New & $8.18 \pm 0.028$ & $8.09 \pm 0.013$ & 0.0642090 \\
\hline Tundan Old & $7.97 \pm 0.012$ & $7.72 \pm 0.021$ & $0.001706^{*}$ \\
\hline
\end{tabular}

${ }^{*} p<0.05$

\pm Standard error of means(SEM)

halo zones around their colonies on Pikovskaya's Agar is a qualitative characteristic of a phosphatesolubilizing bacterium (Mwajita, Murage, Tani and Kahangi, 2013). After four days of incubation, the diameter of the clear halo zones formed around each colony was measured with a Vernier caliper (Mitutoyo Series 531). All the observations were recorded in triplicates. Halo size was computed by subtracting colony diameter from the halo diameter:

Halo Size $=$ Halo diameter - Colony diameter

The classification on phosphorus solubilization described by Mwajjita et al. (2013) was adapted as follows: 0mm (Non-solubilizer), 1-

Table 3. T test for the endorhizosphere and rhizoplane samples from newly-established and old banana plantations in SOCCSKSARGEN.

$t$ Test for Endorhizosphere vs. Rhizoplane

Mean Microbial counts (in log values)

\begin{tabular}{cccc}
\hline Cultivar & Endorhizosphere $(\mathrm{cfu} / \mathrm{g})$ & Rhizoplane $(\mathrm{cfu} / \mathrm{g})$ & $p$ \\
Bungulan New & $5.04 \pm 0.021$ & $5.29 \pm 0.001$ & $0.006511^{*}$ \\
Bungulan Old & $5.06 \pm 0.015$ & $4.85 \pm 0.024$ & $0.003859^{*}$ \\
Cavendish New & $4.89 \pm 0.037$ & $5.19 \pm 0.014$ & $0.007899^{*}$ \\
Cavendish Old & $5.09 \pm 0.014$ & $4.82 \pm 0.027$ & $0.003637^{*}$ \\
Cardava New & $4.94 \pm 0.027$ & $5.18 \pm 0.015$ & 0.0103890 \\
Cardava Old & $5.01 \pm 0.008$ & $4.93 \pm 0.020$ & 0.6537180 \\
Lakatan New & $4.93 \pm 0.026$ & $5.24 \pm 0.016$ & $0.001371^{*}$ \\
Lakatan Old & $4.93 \pm 0.010$ & $5.03 \pm 0.006$ & $0.002838^{*}$ \\
Tundan New & $4.86 \pm 0.018$ & $5.20 \pm 0.013$ & $0.000204^{*}$ \\
Tundan Old & $4.91 \pm 0.011$ & $5.07 \pm 0.009$ & $0.000467^{*}$ \\
\hline
\end{tabular}

${ }^{*} p<0.05$

\pm Standard error of means (SEM) 
$10 \mathrm{~mm}$ (Low solubilizer), 10-20mm (Intermediate solubilizer), $\geq 21 \mathrm{~mm}$ (High solubilizer).

\section{Qualitative Test for Indole-3-acetic Acid Pro- duction}

A colorimetric technique using Salkowski's method was used to determine the amount of IAA produced by each isolate. Cultures (24-hr old) grown on Nutrient Agar were used for this test. DEV Tryptophan Broth was prepared in sterilized test tubes. One loopful of the $24 \mathrm{hr}$-old bacterial culture was inoculated into the broth medium by gently stirring the loop to disperse the bacterial cells. This test was prepared in triplicate tubes incubated at what temperature for four days. After incubation, $500 \mu 1$ of the supernatant was obtained using a micropipette and dispensed into separate sterile microtubes. Immediately, $1000 \mu 1$ of Salkowski's reagent $(2 \mathrm{ml}$ of $0.5 \mathrm{M} \mathrm{FeCl} 3$ and $98 \mathrm{ml} \mathrm{35 \%}$ HCLO4 solution) was added to the supernatant. The solution was incubated in a dark room. Any pinkish change after the reaction time represents the presence of IAA and were recorded accordingly (Table 1). An uninoculated control was used as a negative control to discern any change in color after the addition of the Salkowski's reagent.

\section{Cultural and Morphological Characterization of the Isolates}

Characteristics of the colonies for each isolate were examined on NA plates incubated at $30 \pm 0.1^{\circ} \mathrm{C}$. After $24-48$ hours of incubation, various characteristics of the colonies such as shape, elevation, margin, and color were recorded (Table 4).

Morphological characterization of each isolate was examined by Gram staining and direct observation of the bacterial cells under the compound light microscope (1000X) and the results were recorded accordingly (Table 4).

\section{Results}

\section{Microbial Populations}

Significant variations in the microbial populations of the newly-established and old banana plantations were observed. The ectorhizospheric soil was found to have significantly higher microbial counts than the plantation soil for all the cultivars in newly-established and old banana plantations that were sampled (Table 2). The Bungulan cultivar grown in newly-established plantation had
$8.04 \pm 0.015-\mathrm{cfu} / \mathrm{g} \quad\left(\sim 1.10 \times 10^{8}\right)$ in the ectorhizosphere in contrast with the $7.90 \pm 0.020-\mathrm{cfu} / \mathrm{g}$ $\left(\sim 1.96 \times 10^{5}\right)$ in the plantation soil with a significant $p$ value of 0.005185 . Likewise, the Bungulan cultivar grown in the old plantation has 7.86 \pm 0.012 -cfu/ $\mathrm{g}\left(\sim 7.2 \times 10^{7}\right)$ in the ectorhizosphere in contrast with the $7.68 \pm 0.020-\mathrm{cfu} / \mathrm{g}\left(\sim 7.1 \times 10^{4}\right)$ in the plantation soil with a significant $p$ value of 0.004643 .

The Cavendish cultivar grown in newlyestablished plantation had $8.25 \pm 0.006-\mathrm{cfu} / \mathrm{g}$ $\left(\sim 1.76 \times 10^{8}\right)$ in the ectorhizosphere in contrast with the $8.15 \pm 0.014-\mathrm{cfu} / \mathrm{g}\left(\sim 1.55 \times 10^{5}\right)$ in the plantation soil with a significant $p$ value of 0.009627 . Similarly, the Cavendish cultivar grown in the old plantation had $8.02 \pm 0.019-\mathrm{cfu} / \mathrm{g}\left(\sim 1.04 \times 10^{8}\right)$ in the ectorhizosphere in contrast with the $7.99 \pm 0.020$-cfu $/ \mathrm{g}$ $\left(\sim 6.6 \times 10^{4}\right)$ in the plantation soil. Both the newlyestablished and old plantation cultivating the Cavendish cultivar had higher microbial population in the ectorhizosphere than the plantation soil.

The Cardava cultivar grown in newlyestablished plantation had $8.25 \pm 0.008$-cfu/g $\left(\sim 1.76 \times 10^{8}\right)$ in the ectorhizosphere in contrast with the $8.05 \pm 0.022$-cfu/g $\left(\sim 1.52 \times 10^{5}\right)$ in the plantation soil with a significant $p$ value of 0.006466 . Likewise, the Cardava cultivar grown in the old plantation had $8.00 \pm 0.013-\mathrm{cfu} / \mathrm{g}\left(\sim 1.02 \times 10^{8}\right)$ in the ectorhizosphere in contrast with the $7.94 \pm 0.012-\mathrm{cfu} / \mathrm{g}$ $\left(\sim 8.5 \times 10^{4}\right)$ in the plantation soil. Both the newlyestablished and old plantation cultivating the Cardava cultivar had higher microbial population in the ectorhizosphere than the plantation soil.

The Lakatan cultivar grown in newlyestablished plantation had $8.08 \pm 0.027-\mathrm{cfu} / \mathrm{g}$ $\left(\sim 1.20 \times 10^{8}\right)$ in the ectorhizosphere in contrast with the $8.05 \pm 0.047$-cfu/g $\left(\sim 1.74 \times 10^{5}\right)$ in the plantation soil. On the other hand, the Lakatan cultivar grown in the old plantation had 7.96 $\pm 0.027-\mathrm{cfu} / \mathrm{g}$ $\left(\sim 9.1 \times 10^{8}\right)$ in the ectorhizosphere in contrast with the 7.93 $\pm 0.011-\mathrm{cfu} / \mathrm{g}\left(\sim 1.08 \times 10^{5}\right)$ in the plantation soil. Both the newly-established and old plantation cultivating the Lakatan cultivar had higher microbial population in the ectorhizosphere than the plantation soil.

The Tundan cultivar grown in newlyestablished plantation had $8.18 \pm 0.028$-cfu/g $\left(\sim 1.53 \times 10^{8}\right)$ in the ectorhizosphere in contrast with the $8.09 \pm 0.013-\mathrm{cfu} / \mathrm{g}\left(1.57 \times 10^{5}\right)$ in the plantation soil. Likewise, the Tundan cultivar grown in the old plantation had $7.97 \pm 0.012$-cfu/g $\left(\sim 9.3 \times 10^{7}\right)$ in the ectorhizosphere in contrast with the $7.72 \pm 0.021$ -cfu/g $\left(\sim 1.17 \times 10^{5}\right)$ in the plantation soil. Both the newly-established and old plantation cultivating the Tundan cultivar had higher microbial population in 
JEEAR, Vol. 1, 2018

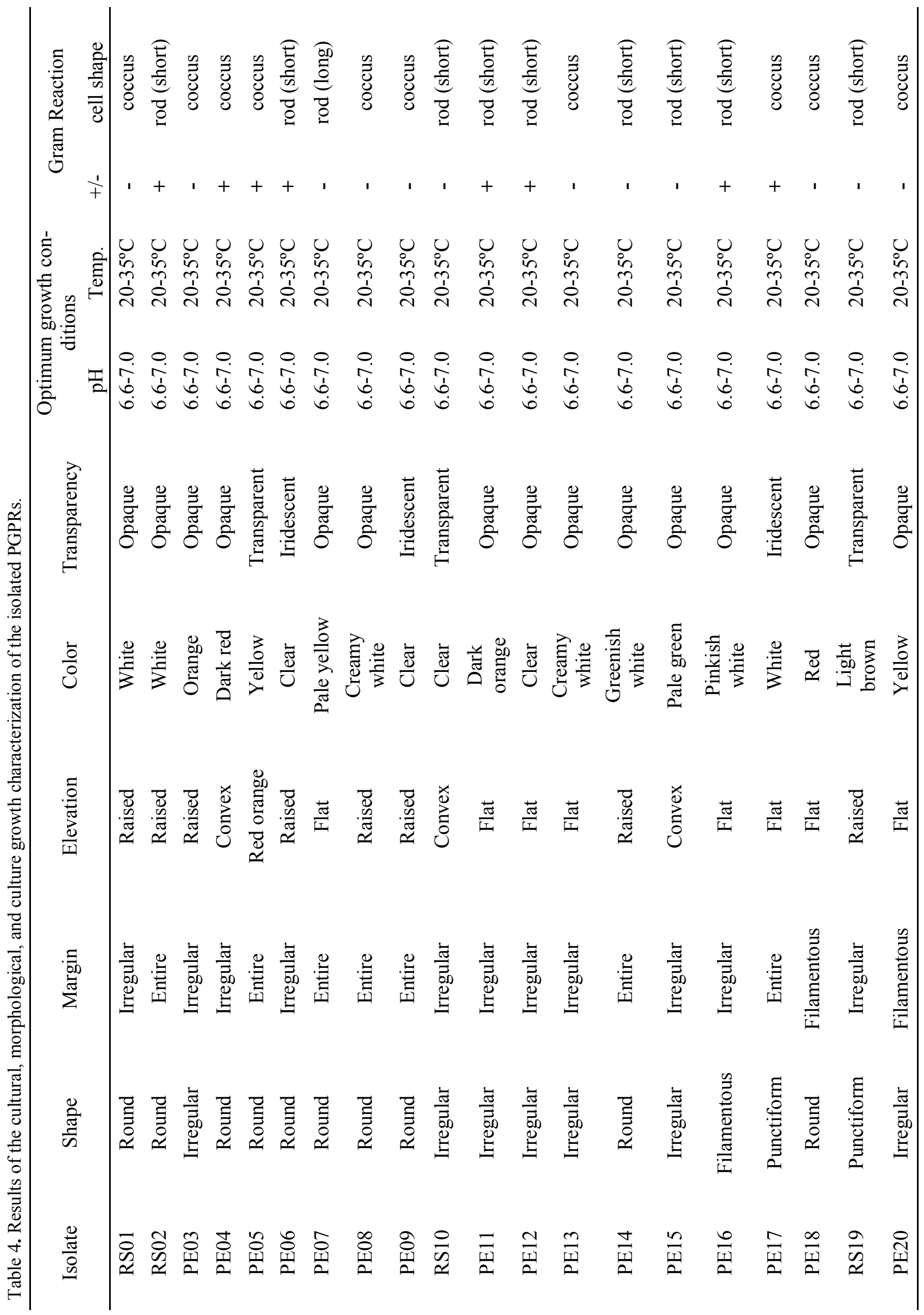


the ectorhizosphere than the plantation soil.

The plantation soil from the newlyestablished plantations was found to have higher microbial counts than the old plantations for all the cultivars. However, the endorhizospheres of old banana plantations are found to have significantly higher microbial populations than that of the newly -established banana plantations (Table 3). In addition, some of the endorhizosphere samples of old plantations also have higher microbial counts than those of the rhizoplane samples of the same plantation (Table 3).

It should be noted that the condition of the soil is one determinant factor for the varying microbial populations of the soil. However, the microbial populations of endophytic bacteria that could colonize the interior of the banana roots can manage to survive since these microorganisms are dependent mostly on the exudates of their host plant for nourishment and are protected from fluctuations in the condition of the soil (Mendes et al., 2013). For the samples retrieved from the banana plantations, the microbial populations from the endorhizospheres of Bungulan, Cavendish and Cardava from the old plantations were found to be higher than those in the rhizoplane of the same cultivars. Furthermore, older plantations were found to have more microbial colonies in the endorhizosphere than the newer plantations in contrast to their microbial populations from the ectorhizosphere. Overall, old banana plantations have higher numbers of microbial populations in the endorhizosphere but have lesser microbial populations in the ectorhizosphere compared with the new plantations (Table 3).

\section{Isolation of Bacteria from Soil and Roots}

A total of 120 bacterial colonies were isolated from the ectorhizosphere, rhizoplane and endorhizosphere samples from the five banana cultivars grown in newly-established and old banana plantations in SOCCSKSARGEN. Seventeen (17) isolates were obtained from the Bungulan cultivar of the newly-established plantation. 10 of which are isolated from the ectorhizosphere, 4 from the rhizoplane and 3 were isolated from the endorhizosphere. There were 12 isolates isolated from Bungulan grown in the old plantation. There were 8 isolates from the ectorhizosphere, 2 from the rhizoplane and 2 isolates from the endorhizosphere.

There were 14 isolates isolated from the Tundan cultivar of the newly-established plantation. 8 were isolated from the ectorhizosphere, 3 were isolated from the rhizoplane and 3 isolates were isolated from the endorhizosphere. There were 7 isolates isolated from Tundan of the old plantation with 3 isolated from the ectorhizosphere, 2 from the rhizoplane and 2 from the endorhizosphere.

A total of 15 isolates were isolated from Lakatan grown in the newly-established plantation. 7 were isolated from the ectorhizosphere, 5 were isolated from the rhizoplane and 3 were isolated from the endorhizoshere. On the other hand, a total of 9 isolates were isolated from the Lakatan grown in the old plantation. 5 were isolated from the ectorhizosphere, 2 were isolated from the rhizoplane and 2 were isolated from the endorhizosphere.

There were 13 isolates isolated from Cavendish of the newly-established plantation. Seven were isolated from the ectorhizosphere, four from the rhizoplane and two from the endorhizosphere. Conversely, seven isolates were isolated from Cavendish grown in the old plantation: four from the ectorhizosphere, two from the rhizoplane and one from the endorhizosphere.

A total of 18 isolates were isolated from Cardava grown on the newly-established plantation. Ten were isolated from the ectorhizosphere, five from the rhizoplane and three from the endorhizosphere. On the other hand, eight isolates were isolated from Cardava grown on the old plantation: four from the ectorhizosphere, two from the rhizoplane and two from the endorhizosphere.

\section{Nitrogen fixation}

Nitrogen fixation is an ability exhibited by most of the PGPR. Nitrogen fixation is one way of converting unusable forms of elemental $\mathrm{N}_{2}$ into an organic, usable form (Gothwal, Nigam, Mohan, Sasmal, \& Ghosh, 2007). Twenty (20) among the $120(17 \%)$ isolated bacteria from the rhizosphere were found to grow in Jensen's medium, a selective medium for the detection and cultivation of nitrogen-fixing bacteria (Table 1). Four of the isolates namely, RS01, RS02, RS10 and RS19 were isolated from the ectorhizosphere. Eight of the isolates, PE06, PE08, PE09, PE11, PE13, PE15, PE17, and PE20 were isolated from the rhizoplane. Eight of the isolates, PE03, PE04, PE05, PE07, PE12, PE14, PE16, and PE18 were obtained from the endorhizosphere.

\section{Phosphate solubilization}

Phosphate solubilization in plants is essen- 
tial since it converts the insoluble forms of phosphate like tricalcium aluminium phosphate $\left(\mathrm{Al}_{3} \mathrm{PO}_{4}\right)$, tricalcium phosphate $\left(\mathrm{Ca}_{3} \mathrm{PO}_{4}\right)$ (Mtambanengwe et al, 2007), and iron phosphate $\left(\mathrm{Fe}_{3} \mathrm{PO}_{4}\right)$ into a soluble organic $\mathrm{P}$ which intensifies the collective performances of plants such as the synthesis of siderophores, production of IAA and gibberellin essential plant hormones responsible for the improvement of plant growth (Khan, Zaidi \& Ahmad, 2014). The occurrence of transparent halo on the cloudy-white media inoculated with the isolates is a positive indication that the bacteria are capable of solubilizing phosphate (Mwajita et al., 2007).

In this study, 19 out of the twenty isolates (95\%) were capable of solubilizing phosphate (Table 1). Only RS01 did not produce any clear zone. The isolates were classified into four groups depending on the halo size: non-solubilizer $(0 \mathrm{~mm})$, low $(1-10 \mathrm{~mm})$, intermediate $(11-20 \mathrm{~mm})$, and high ( $\geq 21 \mathrm{~mm}$ ) solubilizers (Table 1$)$.

Most phosphate-solubilizing isolates were classified as low-solubilizers. These included RS02, PE03, PE04, PE06, PE07, PE08, PE09, PE12, PE14, PE15, PE16, RS19, and PE20. Intermediate solubilizers included isolates PE05, RS10, PE11, PE13, and PE17 (Table 4). One high solubilizer (PE18) was isolated. It has a halo diameter of $26.7 \mathrm{~mm}$.

The five most promising phosphatesolubilizers were thus RS10, PE11, PE13, PE17, and PE18 producing $17 \mathrm{~mm}$ to $27 \mathrm{~mm}$ clear halo zones and were identified as either intermediate or high solubilizer.

\section{Indole-acetic-acid (IAA) Production}

One of the most important options for the qualitative and semi-qualitative determination for the detection of IAA is the use of the technique by Van Urk Salkowski (Ehmann, 1977) which guarantees the presence of the hormone in the supernatant of bacterial cultures or liquid formulations of biological inoculants. As such, the amount of IAA produced by the bacteria on the DEV Tryptophan Broth is within the detectable limits of Salkowski's reagent and can be visually interpreted.

Qualitative assessment of the isolates for indole-3-acetic-acid (IAA) revealed that 17 out of the twenty isolates $(85 \%)$ produced a pinkish coloration after the addition of Salkowski's reagent indicating that these isolates are IAA-producing bacteria. Three isolates were negative for IAA namely RS01, RS02, and PE17 (Table 1).

\section{Cultural and Morphological Characterization}

A total of twenty (20) isolates that were collected from the rhizosphere and roots of banana plants were obtained from various plantations in SOCCSKSARGEN.

Cultural characterization of the isolates revealed that one (1) filamentous, seven (7) irregular, ten (10) round, and two (2) punctiform bacterial colonies were observed in the solid NA medium. Isolates RS01, PE03, PE04, PE06, RS10, PE11, PE12, PE13, PE15, PE16 and RS19 have irregular margins. RS02, PE05, PE07, PE08, PE09, PE14, and PE17 have entire margins. PE18 and PE20 appeared to have filamentous margins. The colony color varied from white, yellow, green, grey, clear, pink and several shades of red and orange. Eight (8) isolates were Gram-positive; RS02, PE04, PE05, PE06, PE11, PE13, PE16, and PE17. Twelve (12) isolates were Gram-negative including, RS01, PE03, PE07, PE08, PE09, RS10, PE12, PE14, PE15, PE17, RS19 and PE20. Ten (10) isolates were cocci. Nine (9) isolates were short rods and one (1) isolate was a long rod (Table 5).

\section{Discussion}

\section{Microbial Populations of the Newly-established and Old Banana Plantations}

Direct plate counting of the ectorhizosphere and plantation soil revealed that newlyestablished banana plantations (1-5 years) have greater populations of bacteria than the old banana plantations ( $\geq 6$ years). A study done by Chen (2004) explains that over-application of inorganic fertilizers and soil mismanagement could result in the decline of helpful microorganisms in the soil and ultimately reduce soil fertility and produce crops that are more susceptible to diseases. All the banana plantations included in this study were reliant on inorganic fertilizers to produce fast growing crops. Application of fertilizers varies from plantation to plantation, with some applying more frequently than others. A common practice is fertilization of banana plants done at least once or twice per month. The older plantations in this study were found to apply fertilizers more frequently than the newer plantations because the soil quality has suffered through time. To compensate for this problem, they apply fertilizers frequently since the banana plants need the necessary nutrients to grow and produce fruits in time for the scheduled harvest. Microbial populations of the older plantations 
indicate that they have lower populations of microorganisms in the soil compared with the newlyestablished ones. However, microbial populations of newly-established plantations would eventually decline with continuous use and oversupply of inorganic fertilizers and soil modifications in agriculture.

The rhizosphere, according to Hartmann, Rothballer, Schmidt, and Hiltner (2008), is a highly favorable habitat for the activity, metabolism and proliferation of numerous microorganisms. Likewise, microbial counting of the plantation soil and the ectorhizosphere reveal that the ectorhizosphere has more diverse populations of bacteria. However, the population of endophytic bacteria found within roots of the banana plants from the old plantations are higher compared with the roots collected from newer plantations. Older banana plantations, specifically older banana plants have higher microbial populations colonizing the roots compared with the younger banana plants from the newly-established plantations. As the banana plant grows, the roots branch out and become larger accommodating more microorganisms in between the free spaces of the cells or the apoplastic space. In addition, the longer the banana plant is cultivated, the more microorganism colonies accumulate within the banana roots. As such, more microbial populations can be found on older banana plants than the recently planted ones.

\section{Potential Isolates for the Plant-growth Promo- tion of Banana Plants}

Majority of the potential isolates isolated from the plantations were isolated on or near the roots of the banana plants. According to Kumar, A. et al. (2012), the various plant-microbe interactions can greatly influence the growth of the plant as well as improve the condition of the soil. Five isolates namely RS10, PE11, PE13, PE17, and PE18 were identified as the most promising isolates which exhibit Nitrogen fixation, Phosphate solubilization and the production of the phytohormone Indole-3-acetic acid (IAA). PGPR, as described by Ogbo and Okongwo (2012), can supply these necessary nutrients to the plant and ultimately improve its growth. These isolates can be potentially utilized as inocula for the production of effective biofertilizers specific for banana plants.

\section{Recommendations}

The five isolates can be used as test inocula in tissue cultured banana plantlets. Root and shoot growth along with other growth parameters should be measured in order to assess whether these isolates can indeed improve the growth of banana plants by comparing the results with the uninoculated tissue cultured banana plants. In addition, these results can also be compared with the banana plants that were applied with the usual inorganic, commercially-available fertilizers. Such methods would imply whether these isolates can indeed be utilized in the mass production of effective biofertilizers which can compete with the inorganic fertilizers in terms of growth promotion in banana plants as an alternate approach to sustainable banana production in plantations. In addition, direct antagonism of the isolates against banana pathogens may also be tested since some PGPR are known to inhibit the growth of certain pathogens promoting healthy, disease-resistant crops.

The soil properties of the rhizosphere and plantation soil like soil $\mathrm{pH}$, amount of organic matter, moisture and soil electrical conductivity (EC) can also be tested along with the temperature and weather readings since these factors can also affect the microbial populations of the soil. In addition, soil sampling can be done on a specified timeline to provide more extensive data on the microbial populations of the soil.

Plant mucilage along with other plant-hostrelated factors that might affect the population of microorganisms in the rhizosphere must also be identified.

To provide more extensive results for $\mathrm{Ni}$ trogen fixation, Indole-3-acetic acid production, and phosphate solubilization, quantitative analysis should be performed.

Lastly, the isolates should be identified down to species level through biochemical and molecular characterization techniques.

\section{Acknowledgement}

The researchers would like to thank the Science Department, College of Natural Sciences and Mathematics, Mindanao State University, General Santos City, Philippines for allowing them to use the facilities required for this research. Gratitude is given to those selected banana plantations in SOCCSKSARGEN for providing the researchers the opportunity to acquire samples and observe their respective areas. This study would not have been completed without their help and cooperation. 


\section{References}

Chen, J.H. (2004). The combined use of chemical and organic fertilizers and/or biofertilizer for crop growth and soil fertility. Department of Soil and Environmental Sciences, National Chung Hsing University, 250 Kuo-Kuang Road, Taichung. Taiwan ROC 2004: 1-9.

Department of Agriculture. (2013). Banana.

Ehmann, A. (1977). The van urk-Salkowski reagent - a sensitive amd specific chromogenic reagent for silica gel thin-layer chromatographic detection and identification of indole derivatives. Journal of Chromatography, 132(2): 267-76

Gothwal R. K., V. K. Nigam, M. K. Mohan, D. Sasmal and P. Ghosh. (2007). Screening of nitrogen fixers from rhizospheric bacterial isolates associated with important desert plants. Applied Ecology and Environmental Research, 6(2): 101-109

Hammer, O., D. A. T. Harper and P. D. Ryan. (2005). PAleontological STatistics (PAST) Software ver. 1.34 .

Hartmann A., M. Rothballer, and M. Schmidt, L. Hiltner, (2008). A pioneer in rhzosphere microbial ecology and soil bacteriology research. Plant Soil, 312: 7-14.

Johnson, L. F. and E. A. Curl. (1972). Method of Research on Ecology of Soil-borne Pathogens. Minneapolis: Burgess.

Khan M. S., A. Zaidi, P. A. Wani. (2006). Role of phosphate-solubilizing microorganisms in sustainable agriculture- a review. Agronomy for Sustainable Development, 29-43.

Khan, M. S., A. Zaidi, E. Ahmad. 2014. Mechanism of phosphate solubilization and physiological samples of phosphate-solubilizing microorganisms. Springer International Publishing Switzerland. DOI 10.1007/978-3-319-08216-2.

Kloepper J.W., and M. N. Schroth. (1978). Plant Pathogenic Bacteria Vol.2. 879-882.

Kumar, A., A. Kumar, S. Devi, S. Patil, C. Payal, and N. Sushila. (2012). Isolation, screening and characterization of bacteria from rhizopheric soils for different plant growth promotion (PGP) activ- ites: an in-vitro study. Recent Research in Science and Technology (RRST), 2012: 1-5.

Mcnear Jr. D. H. (2013). The rhizosphere- roots, soil, and everything in between. Nature Education Knowledge, 4(3):1.

Mendes, R., P. Garveba and J. M. Raajimakers. (2013). The rhizosphere microbiome: significance of plant beneficial, plant pathogenic, and human pathogenic microorganisms. PubMed. 37(5): 634663.

Mtambanengwe, F, P. Kosina and J. Jones. (2007). Organic and inorganic fertilizers. Cereal Knowledge Bank: 1-2.

Mwajita, M. R., H. Murage, A. Tani and E. M. Kahangi. (2013). Evaluation of rhizosphere, rhizoplane and phyllosphere bacteria and fungi isolated from rice in Kenya for plant growth promoters. SpringerPlus 1-9.

Nasrin, S. and M. A. Rahman. (2007). Isolation and characterization of rhizosphere bacteria and their effect on germination of rice seeds and growth of seedlings. Journal of Bio-Science. 15: 77-82.

Ogbo, F. and J. Okongwo. (2012). Some characterstics of a plant growth promoting Enterobacter $s p$. Isolated from the roots of maize. Scientific Research, 2: 368-374.

Tortorra, J.G., B. R. Funke and C. L. Case. (2010). MICROBIOLOGY: An Introduction. 10th Edition. Pearson Education Inc.

van Loon L. C., P. A. H. M. Bakker, and C. M. J. Pieterse. (1998). Systemic resistance induced by rhizosphere bacteria. Annual Review of Phytopathology, 1998: 453-483.

van Loon, L. C. (2007). Plant responses to plant growth promoting rhizobacteria. European Journal of Plant Pathology.

Vessy, J. K. (2003). Plant growth promoting rhizobacteria as biofertilizers. Plant and Soil, 255(2): 571-586.

Vincent, J. M. (1970). A manual for practical study of root-nodule bacteria. IBP Handbook. Oxford: Backwell Scientific Publications. 